\title{
From Medicalisation to Pharmaceuticalisation - A Sociological Overview. New Scenarios for the Sociology of Health
}

\section{Mara Tognetti Bordogna ${ }^{1 *}$}

1 University Milano-Bicocca, Department of Sociology and Social Research, 8 Via Bicocca degli Arcimboldi, Edificio U7, 20126 Milano, Italy

KEYWORDS

Medicalisation

Pharmaceuticalisation

Drugs

Health

Sociology of health

Disease

\begin{abstract}
A BSTRACT
The aim of this paper is to analyse the sociological literature on pharmaceuticalisation and see how sociology helps us understand and explain the phenomenon. We then discuss how sociology, especially in Anglo-Saxon countries, defines the process of pharmaceuticalisation and how this last is evolving. The paper points out that, while medicalisation remains a key concept for health sociology, it is increasingly being queried and/or extended to allow for a techno-scientific era of biomedicalisation (Clarke et al. 2003) and to acknowledge the importance of the pharmaceutical industry in this process (Williams, Martin and Gabe 2011a, 2011b). Particular attention will be paid to the process of pharmaceuticalisation as brought about not just by doctors and their prescriptions, but by the central role of pharmaceutical promoters and the marketing of drugs.
\end{abstract}

\section{Foreword}

Medicaments are complementary to medicine: they support and justify one another. A drug prescribed is a symbolic or real part of the cure. Drugs symbolise the fact that a disease can be treated, the patient is curable. That makes the disease something mentionable, for if there is a drug for a complaint, it becomes 'normal'. The symbolic and the real value of

\footnotetext{
*Contact address: mara.tognetti@unimib.it (M. Tognetti Bordogna)
} 
medication: with the development of multinational pharmaceutical companies, biomedicine, the internet and new epidemics, the terms have undergone a shift of meaning (Terraneo, Sarti and Tognetti Bordogna 2014; Sironi and Tognetti Bordogna 2009). An ever more imposing array of drugs are being prescribed by doctors to contain and control all new forms of pathology and social problems (Zola 1972; Illich 1976), giving rise to a process now known as the medicalisation of society (Conrad, Gabe and Williams 1992).

In addition to the above factors, we are now witnessing the rise of citizen expertise about the diseases of society, and the resort to drugs in order to enhance social performance, relating, and the response to challenge, rather than in response to illness as such. This process has been dubbed the pharmaceuticalisation of society (Williams, Gabe and Davis 2008). It consists in the use of drugs or medication to improve individual performance, without consulting a doctor.

While the medicalisation process has now taken theoretical root in the sociology of health, there is much less familiarity with the attendant concepts of biomedicalisation and pharmaceuticalisation. In this paper we shall be discussing pharmaceuticalisation and how sociology may help understand and explain the phenomenon. We shall be looking at AngloSaxon sociology in particular, for its description of the pharmaceuticalisation process and how it is spreading.

\section{From medicalisation to pharmaceuticalisation}

Conrad was one of the first scholars to define the concept of medicalisation (Conrad 1992; Conrad and Schneider 1992) and describe its impact (Conrad 2007). He sees it as a process by which problems lying outside medicine begin to be treated and defined as medical. He points out that over the last thirty years there has been an increase in 'living issues' being turned into disorders, syndromes connected with behaviour, psychic states or physical conditions. The author wonders whether this is a new epidemic or a new 
ability on the part of medicine to deal with pre-existing issues. Or do we now find medicine diagnosing a range of issues as problems subject to medical treatment, even though there is little clear evidence that they are medical in nature (Conrad 2007). In the name of clarifying the process of medicalisation, Conrad and other authors (Rodeschini 2012) have mounted studies to explore the social basis for this expanding jurisdiction of medicine which forms one of the most powerful late-twentieth-century transformations in the West (Clarke et al. 2003). The 1980s marked the turning point in the medicalisation process, with not only physicians occupying centre-stage in the analysis, but patients, the pharmaceutical industry, the media and the State.

To Conrad (2007, 2009), along with biotechnology and managed care, one of the main factors changing the key mechanisms of medicalisation has been the transformation of patients into consumers. Conrad (2007) also points out the leading part played by technology in the medical process, spurred by the pharmaceutical industry and the manufacturers of biotechnology.

Certain authors in the nineties talked of a process of de-medicalisation. Moynihan and Smith (2002) saw the new information and communication technology as a potent tool for de-medicalisation, since it tends to make the patient more responsible. With the capillary spread of information, people have become more aware of the cost-benefit of medicalising their lives. Others (Ballard and Elston 2005) argue that medicalisation is becoming more and more two-way and multi-dimensional. To listen to Conrad and Schneider (1992), medicalisation is part and parcel of modernity. Elston et al. (2002) wonder whether we are witnessing a historical turning-point towards a post-modern era; that more medicalisation may well be in store.

We note the beginning of a trend among scholars, to whom medicalisation is no longer a sufficient interpretive category to account for the ever more complex medical and social phenomena. Though medicalisation has remained a key concept in the sociology of health, increasingly we see it being challenged, its boundaries stretched to cover a 
techno-scientific era of biomedicalisation (Clarke et al. 2003), while there is increasing recognition of the part being played by the pharmaceutical industry in this process (Williams, Martin and Gabe 2011a, 2011b).

The much-debated change in progress within medicine is well illustrated by the works of Clarke et al. (2003, 2009). Clarke focuses on technology spurring medicalisation; she points out the limitations of classical medicalisation theory and suggests it should be broadened into 'biomedicalisation'. Clarke and Shim (2009) argue that medicalisation no longer explains the full picture emerging from their research and claim that biomedicalisation, taking its cue from medicalisation, shifts the emphasis onto the scope for techno-scientific intervention, (re)organization and transformation.

Picking up from Latour, the two authors suggest that the term 'technoscience' covers the need to see technology and science as 'co-constitutive' (Clarke et al. 2009); they deny the existence of 'pure forms' of scientific research or technology divorced from practical application.

'Techno-science' lends itself, again, to new kinds of intervention, in sickness and in health, in treatment and in the organization of medical therapy, as well as in the way we frame and lead our lives. If medicalisation (Conrad 2007) is about controlling and normalizing human functioning, biomedicalisation (Coveney, Gabe and Williams 2012) focuses on changes in medicine and on the human body: not just to cure, but to personalize, enhance and optimize health. Biomedicine and its tools are of use not just to pathology, but in ensuring better health in future (Clarke et al. 2009).

Today this theoretical framework (medicalisation and biomedicalisation) is itself being questioned by some scholars. Is it sufficient to explain the massive and increasing development and use of drugs, and the ever more powerful role of the pharmaceutical industry, not just in producing and selling, but also in validating their wares (Metzl and Herzig 2007).

Various authors (Abraham 2009, 2010; Bell and Figert 2012) have pointed out that social scientists have long studied drugs and the drug 
industry, but in relation to increasing consumption of the product (Busfield 2006), or in relation to the role drugs have in medicalising society (Williams et al. 2008a). Such authors have seen the crucial step to be recognition of the growing importance of the pharmaceutical industry in medicalisation (Williams et al. 2008). In Conrad's view (2007), although doctors are still watchdogs as to the use of many drugs, the role of the pharmaceutical promoters is on the increase, aggressively targeting the public and not just doctors. While recognising that medicalisation swells the amount of medication used, Abraham (2010) points out that the theoreticians of medicalisation have concentrated on the interaction between the medical professions, patients and public health organizations, but have paid little attention to drugs and the drug industry.

Only in the last ten years, however, have we seen the rise of specific analysis of the political, economic and medical processes leading to use of the term 'pharmaceuticalisation'. The term was first used in anthropology by Mark Nichter (1989) and later in sociology by Williams and his team (Williams, Gabe and Davis 2008). As Bell and Figert have written (2012), the concept of pharmaceuticalisation has largely been developed, in recent years, by Anglo-Saxon scholars who have highlighted various potential aspects of the phenomenon.

\section{Pharmaceuticalisation of life and society}

The process of pharmaceuticalisation is found in milieus that are traditionally not part of the medical domain (Abraham 2010b); it includes the biological effect of chemical substances on the human body, a consumer craze to use technology as a solution to life's problems, and the pharmaceutical industry's interest in augmenting consumption of medicaments (Fox and Ward 2009). Such scholars believe 'we are witnessing the pharmaceuticalisation of domestic life' along with the domestication of pharmaceutical consumption (Fox and Ward 2009). To Williams and Martin (2009), pharmaceuticalisation means the transforming of human skills and 
conditions into pharmaceutical questions of treatment or enhancement. Abraham (2010b) sees it as a process by which social, behavioural or physical conditions are treated or construed by doctors and patients as needing medical drug treatment.

Around these definitions the argument between the medicalisation and the pharmaceuticalisation factions has focused on whether the latter concept is a necessary one or could simply be included under the heading of medicalisation. The debate as it has so far developed may be summed up under three main positions (Busfield 2006; Abraham 2010; Williams, Martin and Gabe 2011a, 2011b). More recently various authors have divided over the relevance of their positions to the complexity of society and to the global situation (Bell and Figert 2012; Williams, Gabe and Martin 2012).

It is Busfield's contention (2006; 2010) that, to understand pharmaceuticalisation, one must focus on the main actors behind the expansion of this process: the pharmaceutical firms, doctors, the public, governments and insurance companies. The pharmaceutical industry calls the tune with the scientists engaged in developing and experimenting with drugs; its strategy is deliberately to generate demand, turn pathology into a market commodity and create new markets for its wares. The doctoring fraternity develops 'new medication', often in league with the pharmaceutical industry, and controls access to the drugs by making them subject to prescription. In its turn, the public in consumer societies use information and communication technology, giving rise to the figure of the 'expert patient' (Busfield 2010). Lastly, governments and insurance companies establish a framework for health care. Busfield thus sees pharmacology as reiterating the global pattern of wealth/poverty, power/inequality. From a commercial standpoint, he argues, the ideal product is one that achieves a patent, is used by a broad spectrum of persons over a long period, and can be sold at a price significantly higher than the cost of producing it. Standard patents last twenty years, he points out, but may in some circumstances be prolonged. For instance, Prozac has been dressed up as Sarafem and is prescribed for Premenstrual Dysphoria 
Disorder. As patents come to an end and brand drugs are replaced by generic drugs, Busfield adds, the growth rates fall worldwide, except for China, Brazil and India.

Abraham (2010b) emphasises that the concept of pharmaceuticalisation is an important one and presents a complex profile. While acknowledging that the term somewhat overlaps with medicalisation, he points out significant differences between the two phenomena. Whereas expansion of drug use affects pharmaceuticalisation per se, the exponents of medicalisation are only interested in how that expansion reflects an increase in the areas of life that used to lie outside medical jurisdiction and are now being presented as medical issues. Abraham echoes Conrad (2007) in claiming that when the US Food and Drug Administration (FDA) changed its rules on direct advertising of drugs and the customer's requirement of a prescription, that made it easier for medicaments that should be prescribed by a doctor to be promoted outside the medical conditions approved by the lawgivers. The change seems to have induced pharmaceutical companies to 'plug' pathologies such as 'generalized anxiety disorders', thereby increasing medicalisation. But, as he argues, the concept of medicalisation is inadequate to explain Conrad's point; he takes the particular example of Ritalin sales. Ritalin has been available since the 1960s, but has increased its sales in the last decade. That might partly be set down to prescription patterns, but it is also due to the fact that medication is now being favoured over psychotherapy in such disorders. The same goes for obesity, which is now increasingly being treated by medication and less by diet or surgery. This all goes to show that pharmaceuticalisation may increase without a rise in medicalisation since, Abraham argues, certain drugs are more and more being used to treat consolidated medical conditions without entailing the transformation of a non-medical into a medical issue. He concludes that pharmaceuticalisation may occur without medicalisation.

This leads Abraham to claim that we need the term pharmaceuticalisation more and more, since medicalisation does not do full justice to the empirical phenomena it purports to describe. Again, 
pharmaceuticalisation may not have increased in all fields of medicine: it is precisely by studying areas of contraction that we can grasp the nature and extent of the phenomenon. He goes on to point out that, as a sociological concept, pharmaceuticalisation must be something more than the simple observation that drugs are increasingly present in society. The factors that he sees as explaining pharmaceuticalisation are biomedicalism (including research, development and innovation by the pharmaceutical industry, and especially the increasing ability of biomedical science to find new pharmaceutical solutions to new or already known diseases), marketing of drugs by the pharmaceutical industry, consumerism, and public policy regulating the sector. Such factors need examining in relation both to the growth and to the contraction of pharmaceuticalisation.

On the question of biomedicalism and its role in the process of pharmaceuticalisation, Abraham points to the steady growth (doubling and tripling in some instances) of some prescription medicaments in the USA, Canada and Australia. In the case of Viagra, sales nearly doubled in the four years following introduction (1998), while Ritalin sales rose five times in the corresponding ten years (1992). The biomedicalist view has taken firm root in industry, techno-science and public opinion, and this makes it possible for anyone suffering from hitherto undiagnosed and untreated conditions like $\mathrm{ADHD}^{1}$, depression or erectile dysfunction to obtain the medication they need. Abraham is not convinced of biomedicalisation tout court in the process of pharmaceuticalisation: not only is it technically improbable, but if we broaden the diagnostic criteria, that may bring about both medicalisation and the discovery of sufferers who were previously undetected. Another weakness of the biomedicalist argument is that pharmaceuticalisation is spurred not so much by scientific discoveries responding to new medical needs, but by an increase in promotion and marketing.

Marketing is a side to the pharmaceutical sector that has grown greatly. Medical experts have been brought into marketing strategy and involved in developing products. Pharmaceutical companies fund meetings

\footnotetext{
${ }^{1}$ Attention Deficit Hyperactivity Disorder (ADHD).
} 
and symposia, and also magazines and magazine articles that speak well of certain drugs. They hire public relations consultants to get the mass media to hype a product, or to block or hold back certain news items.

The key feature of the consumer market is the knowledgeableness of consumers and consumer associations. Abraham (2010) sees this as not necessarily boosting pharmaceuticalisation: it may breed antagonism or collaboration, or both. Drug consumers have been seen (Bell and Figert 2012) as either injury-oriented adversaries or access-oriented collaborators. The former believe they have been harmed by a drug and mount campaigns in the media and the law courts against the manufacturers - a practice that is now widespread in the USA. Antagonism by consumers does not increase pharmaceuticalisation, and may reduce it by sowing doubt as to a drug's safety. Consumer collaborators, on the other hand, believe that medicaments should be available to a wider number of patients. Their behaviour tends to pharmaceuticalisation, since pressure groups in favour of faster access to a drug will work on government agencies to speed up approval of the new product. Abraham argues that if active consumer groups are backed by pharmaceutical companies, the process of pharmaceuticalisation they stimulate will outweigh the de-pharmaceuticalisation by consumer adversaries.

A further boost to pharmaceuticalisation is given by de-regulation policies and especially by national bodies allowing the drug markets to expand.

To Abraham the main driving force comes from industrial marketing which causes pharmaceuticalisation to outstrip medicalisation. It also surpasses the biomedical booster mechanism, which he sees as a weak explanation. Marketing efforts have far exceeded research and development, while the pharmaceuticalisation of low-yield/high health-need therapy areas has remained constant or diminished. The weakness of biomedicalism as an explanation for growing pharmaceuticalisation, and the relative increase in cases of drug-related damage are of more than academic interest. They show that augmented pharmaceuticalisation is not fuelled mainly by 
an increased pharmaceutical ability to meet and foresee health needs. It is rather the sociological factors of consumerism, state de-regulation policies, the commercial priorities of industry, the promotion of products and medicalisation that have expanded pharmaceuticalisation way beyond any such ability (Abraham 2010).

Williams, Martin and Gabe (2011b) take a quite different line. Starting out from medical sociology studies, they propose a broader conceptual framework for pharmaceuticalisation than Busfield and Abraham adopt. Williams' theories take their cue from science and technology studies (STS) as well as health sociology. Adopting a post-modern approach, he defines pharmaceuticalisation as a dynamic, complex, heterogeneous socio-technical process forming part of what we might call a pharmaceutical regime. This may be seen as the network of institutions, organizations, actors and artefacts, as well as the cognitive structures associated with creating, producing and using new therapeutic products. This regime has been built around the development of pharmaceutical products ever since they were introduced in the nineteenth century, and centres on the chemical technology represented by the pill. One of the basic dynamics of this regime is its 'continuous commercial, clinical and geographic expansion' (Williams, Martin and Gabe 2011b). This all ties up with a macro level (developing, experimenting with and regulating drugs) and a micro level (use of drugs in medical practice and daily life). Williams and team see pharmaceuticalisation as a multi-dimensional, multi-level concept and do not rule out de-pharmaceuticalisation, or indeed forms of social resistance to pharmaceuticalisation. They see it as a complex, dynamic process building up a long-term pharmaceuticalisation regime. This is still in progress and includes various distinct socio-economic activities and actors, such as: doctors, patients, consumers and regulators. The degree and extent of pharmaceuticalisation may vary from case to case and depends on the context and on interaction among various groups of actors (Williams, Martin and Gabe 2011b).

Williams thinks pharmaceuticalisation is not only on the increase but 
is a full-blown scientific and social concept. At least six social dimensions (Williams, Martin and Gabe 2011a) need to be studied in analysing the trends and transformations by which society is pharmaceuticalised: (1) redefining and reconfiguring health problems as amenable to pharmaceutical solution, (2) forms of governance in constant change: globalization and the new role of regulatory agencies in promoting innovation, (3) health problems being re-framed by the media and in popular culture as solvable by pharmaceutical means, (4) creating new techno-social identities and mobilising patients and consumer groups with regard to drugs, (5) use of non-medical medicaments and creating new consumer markets, (6) pharmaceutical innovation.

At the root of pharmaceuticalisation, the argument runs, there is a steady increase in the sales and production of medicaments in all countries, the chronicising of health problems, and medicalisation of everyday life. This last position is shared with Conrad (2007) who maintains that pharmaceutical firms sell disease as well as medication. Disease has become commodifiable, as defined by Moynihan and Smith (2002): the social sense of disease is being replaced by the commercial sense of it, including the turning of minor daily problems into medical problems, considering risks as a disease, hiking estimates in order to maximise markets, and lastly aiming publicity at the end-user.

The second set of factors stems from the changing relations between regulatory agencies and the pharmaceutical industry following measures such as reforms reducing the legal obstacles or making regulatory agencies more dependent on the pharmaceutical industry; new policies increasing the role of regulatory agencies in pharmaceutical promotion and innovation, globalization of consolidated models of governance based on pharmaceutical industry interests (Williams, Martin and Gabe 2011a), especially in the developed world. A number of sociology studies (Abraham 1995, 2009, 2010a, 2010b) on anti-inflammatory drugs, anti-depressants and sleeping tablets show that pharmaceutical firms in some cases have a privileged channel to the regulatory agencies. Other studies have dealt with 
the role of regulators vis-à-vis the patient demand to speed up approval of new drugs (Daemmrich 2004). Others again show that regulation of drugs does not always manage to benefit public health. The close link between state offices and pharmaceutical companies (Williams Martin and Gabe 2011a) has led to schemes to reduce the time of reviewing newly patented medicaments, and to ultra-fast approval of drugs for 'serious' diseases or for 'life-threatening conditions' on the basis of fewer data than would properly suffice to demonstrate a product's safety and efficacy. By this last practice some $14 \%$ more drugs have been approved in the last fifteen years (Garattini and Bertele 2001). Williams and his team argue that, in following these measures, regulatory agencies have gone from being guardians of public health, to holders of the key to promoting innovation. There is meanwhile globalization of the Western regulatory system by the creation of bodies such as the International Conference on Harmonisation which pools regulators from Europe, Japan and America. The globalization process is also boosted by new markets opening in emerging economies, and by contracting out drug development to developing countries where experimentation costs are lower than in the West.

On the third point, a large part is played by the media featuring old and new syndromes on programmes and news coverage (for example, restless leg syndrome). Their role as 'presenters and amplifiers' of issues, along with forms of occult advertising, helps to boost pharmaceuticalisation. According to Martin (2006), one should not underestimate pill or capsule design, either: it tunes in to the potential consumer's wavelength via television or the printed word. The new media and the Internet are likewise coming to play an increasing role in the pharmaceuticalisation process, as sources of information about specific products, and also as channels of direct purchase. Fox and Ward (2009) think the consumption of medicaments is being domesticated by computer-mediated access, and that everyday life is itself being pharmaceuticalised in that pills are now seen as 'magic bullets' against a range of daily problems. Williams and team (2011a) say that the Internet may cut two ways in the process of medicalising and 
pharmaceuticalising society: it may open up new channels of pharmaceuticalisation, but also give rise to forums of resistance.

The fourth point about new social identities concerns patients/consumers' growing expertise about their own health. They are now informed actors assessing risks and benefits, taking informed decisions about their own treatment since the relevant information is 'out there' on line, at the click of a mouse. Internet users may also form into communities, self-help groups (Rossi and Tognetti Bordogna 2013). All of this has implications for the individual's sense of self (Rose 2007), as well as the role of individuals in the public domain. Here again, there is scope for pharmaceuticalisation being boosted without doctor mediation, but also for resistance to the phenomenon. As we have said à propos of Abraham (2009), the real effectiveness of patient activism or collective consumer mobilisation depends whether they are supporting or opposing the pharmaceutical industry's basic interests. The latter has also been known to capture patients' and consumers' allegiance (Jones 2009) by informing and educating them. The words of expert patients have proved especially useful in pharmaceutical campaigns. Clearly the process of patient-induced pharmaceuticalisation is likely to be the greater when the treatment being sought is urgently needed.

Another form of pharmaceuticalisation of everyday life is the use of drugs for non-medical purposes (fifth factor): the enhancement of health in the healthy. Here people are driven by a desire for self-improvement, improving their own performance. Such behaviour is classed as enhancement, though the literature divides on this (Elliot 2003). Conrad (2007) thinks we should distinguish three types of enhancement bound up with normalisation, in which biomedical enhancement is used by doctors and patients to bring the body up to society's standards of normality; repair, where biomedical treatment is used to adjust and/or rejuvenate the body to its previous shape; and lastly, the desire to boost individual performance to ensure competitive advantage. Once again we find medicalisation and 
pharmaceuticalisation together; in the second case, there is no involvement of doctors in the phenomenon.

There has been keen interest in the promise of new drugs to enhance cognitive performance. But if medicines are presented as boosters (Williams, Martin and Gabe 2011a), that may create new markets for drugs sold straight to the consumer without medical control.

Lastly, the sixth factor, pharmaceutical innovation and the creation of new future health scenarios. This includes areas that fall under the sociology of innovation and especially the phenomena of invention and creation: setting up an expectation that some future possibility may be fulfilled. In other words, patients are induced to invest indirectly and collectively in future pharmaceutical discoveries to treat the complaints they are suffering from (Novas 2006). This involves the field of genetic- and genomic-medicine that Williams uses as an example, entailing great speculation as to a new era of personalized or tailor-made medicine, targeting the individual genetic profile. In this case one imagines a considerable reduction of hostility to drugs - a traditionally common feature: they here hold out the hope of greater effectiveness in being tailored to specific genotypes. Pharmaceutical innovation of this kind bears on policy decisions and on a future vision of health. Williams thinks that such pharmaceuticalisation of the future may help keep the ball in the biomedical court, creating investment and innovation in the quest for new medicines as the best way of improving human health. But how new pharmaceutical technology translates into practice is a far more complex matter. Pharmacological data of the kind described above are finding their way into all stages of research and development. For the time being, progress is slow and patchy, with little evidence of enormous benefit of the kind expected (Williams, Martin and Gabe 2011a, 2011b). Study and research on this scale conjures up thoughts of market segmentation, the proliferation of genetic experimentation, even racial policies. Despite the investment in research and the broadening of the canvas with drugs deriving from genomics, Williams and colleagues feel that pharmaceutical innovation is marking time. Confidence in the 
revolution of biotechnology remains high, all the same, a fact that sociologists of expectation should view with a critical eye. For the sociology of expectation, as they well know, teaches that we must examine our own expectations as partners in the field in question, including the various future pharmaceutical scenarios we claim to be analysing (Williams, Martin and Gabe 2011a, 2011b).

The six sides to pharmaceuticalisation listed by Williams et al. have certain features in common, such as: expansion of the drug market beyond traditional areas, both geographical (the developing world) and applicatory (healthy persons); the growing scope for regulation; the constant bid to get round medical control and set up direct contact with patients/consumers; and lastly, colonization of the world of life. These are all specific features of pharmaceuticalisation, enabling us, incidentally, to distinguish it from medicalisation. What emerges is the central role of the pharmaceutical industry, eluding medical control and reframing the role of the patient and/or consumer. It also follows that pharmaceuticalisation has increasing analytical value as a sociological concept; likewise that it is important to study what the pharmaceutical industry is getting up to, it being the prime actor in contemporary biomedicine. Pharmaceuticalisation may claim to be a new frame of interpretation for the sociology of health, and one likely to yield new prospects.

Williams concludes his work by suggesting that, amid the welter of approaches adopted to date - political-economic and realist, elements of social constructionism, STS studies, Foucault and Habermas approaches -, we should leave the door open for the time being on our various interpretations of and theories about pharmaceuticalisation, since it is still premature, if not useless, at this stage to single out any specific yardsticks of interpretation. Many important prospects of research are in the pipeline, for example: the role of industry in expanding pharmaceutical markets to include new non-medical conditions or complaints; the changing role of regulatory agencies; new thoughts on the role of patients and consumers in the development and use of drugs. Or again: how the world of life, everyday 
life and the future of health are coping with colonization by pharmaceutical firms and their 'solutions'. Last but not least, what role sociologists may have as co-producers of issues regarding the pharmaceuticalisation of society. The conceptual framework, then, is well delineated, but it leaves great scope for in-depth studies and research.

In spring-summer 2012 Social Science and Medicine carried an interesting exchange of views between Bell and Figert (2012) and Williams, Gabe and Martin (2012). In reviewing the debate on medicalisation and pharmaceuticalisation, Bell and Figer argued that since we live in a postmodern society, we need a post-modern theory (or set of analysis tools) enabling us to explain hybrids: we can no longer pretend there is any radical difference between the human and the material world. Yet modern theories are unable to explain hybrids, or the collapse of basic boundaries between humans and animals, organisms and machines, physical and non-physical entities. In the second place, it is less and less likely that nation-States will mediate where economic, political and social processes are concerned; hence we need to look 'above' the State towards extra-state rules and 'below' the State at the movements of people, technology and ideas, if we wish to understand how processes such as pharmaceuticalisation work (Bell and Figer 2012). This gives central importance to the issue of globalization and choice of country, as well as pharmaceutical companies and patients/consumers. Referring to the work of anthropologists, Bell and Figer (2012) complain that sociologists are still too Western-biased in studying the issue of pharmaceuticalisation. It was anthropologists in fact (Petryna 2006), who introduced the notion of 'pharmaceuticalising public health' into the case study on drugs that connect global dynamics among states, NGOs and pharmaceutical companies with local communities. They cite the example of the Brazilian policy (Biehl 2008) for preventing and treating AIDS by free distribution of ARV to all registered cases of AIDS. This policy has reduced AIDS mortality and the demand on hospital services, as well as improving the lives of HIV/ AIDS sufferers. By designating AIDS as a 'national disease', Brazil has set up a 'captive market' for the pharmaceutical industry, not just 
for already available drugs, but also for the future, seeing that new drugs are being developed to replace 'old treatment protocols' when these lose effectiveness (Biehl 2008). Another instance that they cite of pharmaceuticalising public health is the treatment of asthma sufferers in Barbados (Whitmarsh 2008).

Williams, Gabe and Martin (2012) came back in critical vein. Studies by sociologists on pharmaceutical firms and products date back to the mid1980s, before the term pharmaceuticalisation was coined. They acknowledged the contribution of anthropologists, but warned that one should not assume that all anthropological research into the world's South was part of a post-modern turning-point. They (Williams and colleagues) maintained there are many other factors to consider in the process of pharmaceuticalisation, such as resistance by consumers/patients, depharmaceuticalisation, the challenge posed by restructuring pharmaceutical industries, outsourcing to developing countries and conducting trials there. They ended by calling for a framework within which to cover the full complexity and global aspects of the problem. This especially meant paying attention to resistance and ambivalence, the constant role of the doctor-drug link, the crisis of innovation in industry and the contribution of research both in the North and in the South.

\section{Conclusions}

We have discussed the need to move beyond and extend the notion of medicalisation and embrace that of pharmaceuticalisation which better fits the new phenomena of consumption, production and marketing of drugs. We are witnessing a new theoretical and analytical dimension, and pharmaceuticalisation still has points of definition and theory that need clarifying and consolidating, however much Williams may regard it as a fully-formed social and scientific concept (Williams et al. 2012). The phenomenon proves to hinge on the role of drug production and marketing. 
We went on to show how in the Anglo-Saxon debate the notions of medicalisation and pharmaceuticalisation are not always mutually exclusive, but frequently highlight different features. In analysing the debate in progress, we find that our present society contains at one and the same time phenomena of pharmaceuticalisation and of de-pharmaceuticalisation, as well as pharmaceuticalisation of public life.

We have taken our cue from the arguments of the main theoreticians of this subject, and gone on to analyse from differing perspectives the various sociological dimensions upon which the concept of pharmaceuticalisation rests.

Lastly, our article has shown how the phenomenon of pharmaceuticalisation is important to understand the pattern of medicament consumption in our society, and also the roles of the various actors in the health, wellness and illness settings, not forgetting individuals' concern with their own performance. This enables the analysis to cover the role of actors on the micro plane (the individual), the middle plane (the relation between individuals and their doctor, the degree of performance society expects of them, and the pharmaceutical companies) and the macro plane (globalization of our drug-conscious society and public health policies of deregulation or pharmaceuticalisation).

\section{Limits and future prospects}

This paper does not claim to be exhaustive or generalizable: it is mainly a survey of the literature and the debate over theory, and is hence not backed up by systematic research findings. It also focuses largely on the AngloSaxon literature. While aware of these limitations, we feel it may nonetheless provide a useful summary of the debate and a starting point for investigation of the phenomenon, whether in Anglo-Saxon countries or the rest of the world, and especially in the BRICS countries. In future we believe that studying the process of pharmaceuticalisation and depharmaceuticalisation will assume increasing importance in the sociology of health. Via such studies we will be able to analyse the various new forms of 
aggregation and participation by individuals, and the different forms of aggregation linked to health and disease.

\section{References}

Abraham, John. 1995. Science, Politics and the Pharmaceutical Industry. London: Routledge.

Abraham, John. 2008. "Sociology of pharmaceuticals development and regulation: a realist empirical research programme." Sociology of Health $\mathcal{E}$ Illness 30(6): 869-885.

Abraham, John. 2009. "The pharmaceutical industry, the state and the NHS." In The New Sociology of the Health Service, edited by Jonathan Gabe and Michael Calnan, 99-120. London: Routledge.

Abraham, John. 2010a. "The Sociological Concomitants of the Pharmaceutical Industry and Medications." In Handbook of Medical Sociology, edited by Chloe Bird, Peter Conrad, Allen Fremont and Stefan Timmermans, 290-308. Nashville: Vanderbilt University Press.

Abraham, John. 2010b. "Pharmaceuticalization of Society in Context: theoretical, empirical, and health dimensions." Sociology 44(4): 603622.

Ballard, Karen and Mary Ann Elston. 2005. "Medicalisation: A Multidimensional Concept." Social Theory and Health 3(3): 228-241.

Bell, Susan and Anne E. Figert. 2012. "Medicalization and Pharmaceuticalization at the Intersections: Looking Backward, Sideways and Forward." Social Science E Medicine 75(5): 775-783.

Biehl, João. 2008. "Drugs for all: the Future of Global AIDS Treatment." Medical Anthropology 27(2): 99-105.

Busfield, Joan. 2006. "Pills, Power, People: Sociological Understandings of the Pharmaceutical Industry." Sociology 40(2): 297-314.

Busfield, Joan. 2010. "A A Pill for Every Ill': Explaining the Expansion in Medicine Use." Social Science E Medicine 70(6): 934-941.

Clark, David. 2002. "Between hope and acceptance: the medicalisation of dying." British Medical Journal 324: 905-907.

Clarke, Adele, Janet K. Shim, Laura Mamo, Jennifer Ruth Fosket, and Jennifer R. Fishman. 2003. "Biomedicalization: Technoscientific Transformations of Health, Illness, and U.S. Biomedicine." American Sociological Review 68(2): 161-194.

Clarke, Adele, Laura Mamo, Jennifer Ruth Fosket, Jennifer R. Fishman, and Janet K. Shim. 2009. Biomedicalization: Technoscience and 
Transformations of Health and Illness in the U.S. Durham: Duke University Press.

Clarke, Adele and Janet Shim. 2009. "Medicalizzazione e biomedicalizzazione rivisitate: tecno-scienze e trasformazioni di salute, malattia e biomedicine." Salute e Società 2 (Fascicolo EN2): 223257.

Conrad, Peter. 1992. "Medicalisation and Social Control." Annual Review of Sociology 18: 209-232

Conrad, Peter. 2007. The Medicalization of Society: On the Transformation of Human Conditions into Treatable Disorders. Baltimore: Johns Hopkins University Press.

Conrad, Peter and Joseph W. Schneider. 1980. "Looking at Levels of Medicalization: A Comment on Strong's Critique of the Thesis of Medical Imperialism." Social Science \& Medicine. Part A: Medical Psychology and Medical Sociology 14(1): 75-79.

Conrad, Peter and Joseph W. Schneider. 1992. Deviance and Medicalization: from Badness to Sickness. Philadelphia: Temple University Press.

Coveney, Catherine, Jonathan Gabe, and Simon Williams. 2012. "Potenziamento della capacità mentale? Dalla medicalizzazione della cognizione alla farmacologizzazione delle routine mental life". Salute e Società 2 (Fascicolo suppl. 2): 145-159.

Daemmrich, Arthur. 2004. Pharmaco Politics. Chapel Hill: University of North Carolina.

Elliot Carl. 2003. Better Than Well: American Medicine Meets the American Dream. New York: W. W. Norton.

Elston, Mary Ann, Jonathan Gabe, David Denney, Raymond Lee, and Maria O'Beirne. 2002. "Violence against Doctors: a Medical(ised) Problem? The Case of National Health Service General Practitioners." Sociology of Health $\mathcal{E}$ Illness 24(5): 575-598.

Fox, Nick and Katie Ward. 2009. "Pharma in the Bedroom and the Kitchen. The Pharmaceuticalisation of Daily Life." Sociology of Health $\mathcal{E}$ Illness 30(6): 856- 868.

Garattini, Silvio and Vittorio Bertele. 2001. "Adjusting Europe's Drug Regulation to Public Health Needs." The Lancet 358(9275): 64-67.

Illich, Ivan. 1976. Medical Nemesis. New York: Pantheon; Ital. trans. 2005. Nemesi medica. L'espropriazione della salute. Milano: Boroli Editore.

Jones, Kathryn. 2009. "In Whose Interest? Relationships between Health Consumer Groups and the Pharmaceutical Industry in the UK." In Pharmaceutical and Society: Critical Discourses and Debates, edited by 
Simon J. Williams, Jonathan Gabe and Peter Davis, 112-125. Oxford: Blackwell.

Martin, Paul. 2006. "The Pharmaceutical Person." BioSocieties 1:.273-287.

Metzl, Jonathan and Rebecca Herzig. 2007. "Medicalisation in the 21st Century: Introduction." The Lancet 369(9562): 697-698.

Moynihan, Ray and Richard Smith. 2002. "Too Much Medicine? Almost Certainly." British Medical Journal 324(7342): 859-860.

Nichter, Mark. 1989. "Pharmaceuticals, the Commodification of Health, and the Health Care-medicine Use Transition." In Anthropology and International Health: Asian Case Studies, edited by Mark Nichter and Mini Nichter, 265-326. Amsterdam: Gordon and Breach Publishers.

Novas, Carlos. 2006. “The Political Economy of Hope: Patients' Organizations, Science and Biovalue." BioSocieties 1: 289-305.

Petryna, Adriana. 2006. “Globalizing Human Subjects Research." In Global Pharmaceuticals: Ethics, Markets, Practices, edited by Adriana Petryna, Andrew Lakoff, and Arthur Kleinman, 33-60. Durham: Duke University Press.

Rodeschini, Giulia. 2012. "Curare gli anziani: pratiche di cura in tensione tra processi assistenziali e di medicalizzazione”. PhD Diss., Università degli Studi di Trento, Scuola di Dottorato in Sociologia e Ricerca Sociale.

Rose, Nicholas. 2007. The Politics of Life Itself. Princeton: Princeton University Press.

Rossi, Paolo and Mara Tognetti Bordogna. 2013. "Mutual help without borders? Plurality and heterogeneity of online mutual help practices for people with long-term chronic conditions." The European Journal of Social Work 17(4): 523-538.

Sironi, Vittorio and Mara Tognetti Bordogna. 2009. "La politique du médicament en Italie: histoire et perspectives." Revue Sociologie Santé 30: $65-80$.

Terraneo, Marco, Simone Sarti, and Mara Tognetti Bordogna. 2014. "Social Inequalities and Pharmaceutical Cost Sharing in Italian Regions." International Journal of Health Services 44(4): 761-785.

Whitmarsh, Ian. 2008. "Biomedical ambivalence: Asthma Diagnosis, the Pharmaceutical and Other Contradictions in Barbados." American Ethnologist 35(1): 40-63.

Williams, Simon, Jonathan Gabe, and Peter Davis. 2008. "The sociology of pharmaceuticals: progress and prospects." Sociology of Health $\mathcal{E}$ Illness 30(6): 813-824. 
Williams, Simon J., Clive Seale, Sharon Boden, Pam Lowe, and Deborah Lynn Steinberg. 2008. "Waking up to sleepiness: Modafinil, the media and the pharmaceuticalisation of everyday/night life." Sociology of Health E Illness 30(6): 839-855.

Williams, Simon J. and Paul Martin. 2009. "Correspondence on cognitive enhancement drugs for the healthy: risks and benefits may turn out to be finely balanced." Nature 457: 532 .

Williams, Simon J., Paul Martin, and Jonathan Gabe. 2011a. "The pharmaceuticalisation of society? A framework for analysis." Sociology of Health E Illness 33(5): 710-725.

Williams, Simon J., Paul Martin, and Jonathan Gabe. 2011b. “Evolving sociological analyses of pharmaceuticalisation: a reply to Abraham Sociology of Health \& Illness 5: 729-730.

Williams, Simon J., Jonathan Gabe, and Paul Martin. 2012. “Medicalization and pharmaceuticalization at the intersections: A commentary on Bell and Figert." Social Science \& Medicine 75(12): 2129-2130.

Zola, Kenneth. 1972. "Medicine as an Institution of Social Control." Sociological Review 20(4): 487-504. 